Liapounoff and Cartan. 'The main part of this book consists of a critical re-presentation of the essential theorems obtained by these writers, with some account of the special mathematical methods required. Here again, note should be taken of the general usefulness of Dr. Lyttleton's admirable summary of ellipsoidal harmonic analysis.

The results are, briefly, that the Maclaurin spheroid is thoroughly stable for $H<H_{0}$, but the secular stability passes to the Jacobi ellipsoid at $H=H_{0}$. The ellipsoid is thoroughly stable for $H_{0}<H<H_{1}$ and thoroughly unstable for $H>H_{1}$. The pearshaped figure is secularly unstable ; it cannot, therefore, arise physically, and questions about its mathematical continuity with other forms have no physical significance.

The evolution of a rotating mass of liquid with constant angular momentum and slowly increasing density is the same as that of a mass with constant density and slowly increasing angular momentum. If, then, a rotating mass of liquid (with non-vanishing viscosity) is contracting slowly from an initial state of sufficient distension, it will evolve through the series of Maclaurin spheroids, until an ellipsoidal configuration is possible, and then through the series of Jacobi ellipsoids, until the last stable ellipsoidal configuration is attained. It will not then pass into a pear-shaped configuration and will not undergo fission into two bodies describing periodic orbits about each other. It must almost certainly break up, in some way which is not yet calculable, but the fragments must ultimately acquire orbits leading to infinite separation. These conclusions were first correctly formulated by Dr. Lyttleton himself and are cogently stated in his final chapter on "Cosmogonical Implications". This chapter offers some constructive suggestions about the possible rotational disruption of primitive planets and the formation of satellites in the solar system. But many readers will be more interested in the demonstration that binary stars cannot have been formed by rotational fission. A uniform liquid mass is, of course, an unrealistic representation of an actual star, but certain of Dr. Lyttleton's arguments are not restricted to this case and suffice to establish the result generally. In this connexion, Dr. Lyttleton justifiably criticizes some of Jeans's interpretations of the stability theory; but it should be more widely known that, for reasons other than Lyttleton's, Jeans himself rejected the fission theory of binary stars ("Universe Around Us" (fourth ed., Cambridge, 1944); pp. 227-235).

Dr. Lyttleton's book is clearly going to be the standard work on a subject that must form the basis for future investigations which can be expected to be of great significance.

W. H. MCCreA

\section{WRITING FOR ENGINEERS}

\section{Engineers as Writers}

Growth of a Literature. Edited with Introductions and Critical Comments by Walter J. Miller and Leo E. A. Saidla. Pp. xii +340. (New York and Toronto : D. Van Nostrand Company, Inc.; London: Macmillan and Co., Ltd., 1953.) 32s. net.

THE reviewer naturally turns with special interest to the last section of this book, entitled "Sugges tions for Review of this Book", only to discover that the word is used with the common American meaning of 'second view' - what the English student would call 'revision'. This little disappointment serves to emphasize the basically American outlook of the compilers of this volume, which is a collection of reports, lectures, papers and extracts from books, all written by engineers. Threo of the pieces selected are American translations of Latin authors (Frontinus, Vitruvius and Agricola), four of them are from English engineers of the eighteenth and nineteenth centuries (Smeaton, McAdam, Rankine and Parsons), while the remaining eight selections are by Americans (from Wellington, the railway economist, to Ammann, designer of the George Washington Bridge). Even with the earlier work, there is a striking contrast between the English and American idiom, which becomes progressively more marked.

It is generally acknowledged that every effort should be made to train engineering students in clear self-expression, and this collection has been made as an attempt to assist in attaining this object. As the book is intended for class use in engineering schools, the authors have made comments with each chapter and have added suggestions for study and some introductory remarks. Literary criticism of some of the selections included is disarmed by the fact that the authors themselves adopt the attitude that "any study of engineers as writers would be valueless if we did not consider their weaknesses along with their strengths".

The authors have clearly devoted much labour to the selection of their material, as is evidenced by the acknowledgments to no fewer than fifty individuals who have assisted in the undertaking. The result is an undoubtedly interesting collection of items, which it would be inconvenient (though perhaps a valuable experience) for the student himself to extract from the library shelves, were he merely given instead adequate references to each of them. Unfortunately, library facilities would be overwhelmed if an attempt were made to adopt such a scheme in class.

The most serious doubt which comes to mind, on reading this book, is whether the study of such a heterogeneous collection is, in fact, likely to assist a student to clearer, and hence better, writing of his own. Surely the approach most likely to be successful consists of an exhaustive analysis of the methods available for organizing and presenting material, followed by the most thorough criticism of his own efforts at writing and plenty of practice. But there is no reason why a book such as this might not, with some students, act as a stimulus to better writing.

R. H. MACMILLAN

\section{SOCIAL INSECTS}

The Social Insects

By Dr. O. W. Richards. Pp. $219+51$ plates. (London: Macdonald and Co. (Publishers), Ltd., 1953.) 15s. net.

THE need for an authoritative, up-to-date account of the behaviour of social insects in general has become increasingly apparent in recent years, during which the study of the social insects has attracted much attention.

As Prof. Richards himself points out at the beginning of his book, it is to-day quite impossible for any one worker to have made personal observation on all the species of social insects or to have seen all the 